\title{
Ancient Human Parasites in Ethnic Chinese Populations
}

\author{
Hui-Yuan Yeh ${ }^{1,2}$, Piers D. Mitchell ${ }^{1, *}$ \\ 'Department of Archaeology and Anthropology, University of Cambridge, The Henry Wellcome Building, Cambridge CB2 1QH, UK; \\ ${ }^{2}$ School of Humanities and Social Sciences, Nanyang Technological University, 637332, Singapore
}

\begin{abstract}
Whilst archaeological evidence for many aspects of life in ancient China is well studied, there has been much less interest in ancient infectious diseases, such as intestinal parasites in past Chinese populations. Here, we bring together evidence from mummies, ancient latrines, and pelvic soil from burials, dating from the Neolithic Period to the Qing Dynasty, in order to better understand the health of the past inhabitants of China and the diseases endemic in the region. Seven species of intestinal parasite have been identified, namely roundworm, whipworm, Chinese liver fluke, oriental schistosome, pinworm, Taenia sp. tapeworm, and the intestinal fluke Fasciolopsis buski. It was found that in the past, roundworm, whipworm, and Chinese liver fluke appear to have been much more common than the other species. While roundworm and whipworm remained common into the late 20th century, Chinese liver fluke seems to have undergone a marked decline in its prevalence over time. The iconic transport route known as the Silk Road has been shown to have acted as a vector for the transmission of ancient diseases, highlighted by the discovery of Chinese liver fluke in a 2,000 year-old relay station in northwest China, $1,500 \mathrm{~km}$ outside its endemic range.
\end{abstract}

Key words: Clonorchis sinensis, Schistosoma japonicum, archaeology, helminth, mummy, paleoparasitology, parasite, Silk Road, China

\section{INTRODUCTION}

The aim of this paper is to discuss the evidence for intestinal parasites in past human populations of Chinese ethnicity in order to better understand which species were most common and how infection might have varied throughout history. This is an important area of investigation, as such an approach could potentially identify changes in parasitism between hunter-gatherers, farmers cultivating rice or sorghum, the inhabitants of early small towns, and later large cities [1]. There may have been differences in species infecting those people living in the lush, well-watered regions of eastern and southern China compared with the more arid regions of central, northern, and western China. We could even identify the spread of parasites along the Silk Road and other trade routes [2].

Some of the publications describing ancient parasites are not widely known outside China as they have been published in regional Chinese journals that may not be easily read or accessed by the international community. Paleoparasitology is a

\footnotetext{
- Received 22 August 2016, revised 28 September 2016, accepted 1 October 2016. *Corresponding author (pdm39@cam.ac.uk) (C) 2016, Korean Society for Parasitology and Tropical Medicine This is an Open Access article distributed under the terms of the Creative Commons Attribution Non-Commercial License (http://creativecommons.org/licenses/by-nc/4.0) which permits unrestricted non-commercial use, distribution, and reproduction in any medium, provided the original work is properly cited.
}

relatively recent field of research in ethnically Chinese regions, compared to the century long tradition in Western countries [3]. In the past, parasite evidence from China has often been obtained from naturally preserved mummies that were analyzed by anatomists or physicians (Table 1). Other methods for sourcing ancient fecal samples, such as the pelvic soil from burials, latrine sediments, and coprolites from rubbish tips have not been widely used. In this paper, we will examine the evidence for parasites dating from the Neolithic period to the end of the Qing Dynasty (7,000 BCE to CE 1911/1912) (Table 2). This will start to shed light on when, how, and where the ancient communities of the area became infected by the range of parasite species now known in the region [4].

\section{THE EVIDENCE FOR PARASITES IN CHINA THROUGH THE AGES}

\section{Neolithic (7,000-2,000 BCE)}

The earliest proposed evidence for parasites in China dates from the Neolithic period. Three distinct phases of the period have been categorized: the Early Neolithic (7,000-5,000 BCE), the Middle Neolithic (5,000-3,000 BCE), and the Late Neolithic (3,000-2,000 BCE) [5]. Within the first phase, the Jiahu site, located in Henan Province and dated to 7,000 BCE to $5,700 \mathrm{BCE}$, is significant with findings of many artefacts, in- 
Table 1. Summary of Chinese mummies with published parasite studies, adapted from Li (1984)

\begin{tabular}{|c|c|c|c|c|c|c|}
\hline Location & Parasite & Sex & Age & Time period \& dynasty & Social status & Reference \\
\hline Jiangling, Hubei Province & $\begin{array}{l}\text { Clonorchis sinensis, } \\
\text { Trichuris trichiura, } \\
\text { Ascaris lumbricoides }\end{array}$ & $\mathrm{F}$ & unknown & Warring States period & unknown & [16] \\
\hline Changsha, Huibei Province & $\begin{array}{l}\text { Schistosoma japonicum, } \\
\text { T. trichiura, Enterobius vermicularis }\end{array}$ & $\mathrm{F}$ & 50 & Han Dynasty & Wealthy & [16] \\
\hline Phoenix Hill, Huibei Province & $\begin{array}{l}\text { S. japonicum, C. sinenisis, } \\
\text { Taenia sp., T. trichiura }\end{array}$ & M & 55 & Han Dynasty & Wealthy & {$[15,16]$} \\
\hline Jintan, Jiangsu Province & A. lumbricoides, T. trichiura & M & $28-40$ & Song Dynasty & unknown & [16] \\
\hline Hengyang, Hunan Province & C. sinensis & M & 50 & Song Dynasty & unknown & [16] \\
\hline Guangzhou, Guangdong Province & A. lumbricoides & M & 84 & Ming Dynasty & Wealthy & [16] \\
\hline Guangzhou, Guangdong Province & $\begin{array}{l}\text { T. trichiura, C. sinenisis, } \\
\text { Fasciolopsis buski }\end{array}$ & $\mathrm{F}$ & 80 & Ming Dynasty & Wealthy & [16] \\
\hline Yangzhou, Jiangsu Province & A. lumbricoides, T. trichiura & M & unknown & Ming Dynasty & Wealthy & [16] \\
\hline Yangzhou, Jiangsu Province & A. lumbricoides, T. trichiura & $\mathrm{F}$ & 60 & Ming Dynasty & Wealthy & [16] \\
\hline Fuqing, Fujian Province & $\begin{array}{l}\text { C. sinenisis, F. buski, } \\
\text { T. trichiura, A. lumbricoides }\end{array}$ & M & 50 & Ming Dynasty & unknown & [16] \\
\hline Shaowu, Fujian Province & A. lumbricoides & M & 41 & Ming Dynasty & Wealthy & [16] \\
\hline Longyan, Fujian Province & T. trichiura, A. lumbricoides & $\mathrm{F}$ & 74 & Ming Dynasty & Wealthy & [16] \\
\hline Fuzhou, Fujian Province & C. sinenisis, T. trichiura & $\mathrm{F}$ & $50-60$ & Ming Dynasty & Wealthy & [16] \\
\hline
\end{tabular}

Table 2. Time periods and dynasties in China

\begin{tabular}{|c|c|c|c|}
\hline \multicolumn{4}{|c|}{ Neolithic (7000 BCE-2000 BCE) } \\
\hline \multicolumn{4}{|c|}{ Formation of Early States: Erlitou and Erligang (1900/1800 BCE -1250 BCE) } \\
\hline \multicolumn{4}{|c|}{ Shang dynasty (c. 1766/1600/1556 BCE - c.1122/1046 BCE) } \\
\hline \multirow[t]{3}{*}{ Zhou dynasty } & Western Zhou & & 11th century BCE-771 BCE \\
\hline & Eastern Zhou & Spring and Autumn & c. $770 / 771$ BCE -c.475/476 BCE/403 BCE \\
\hline & & Warring States & 5th century BCE-221 BCE \\
\hline \multicolumn{3}{|l|}{ Qin dynasty } & 221 BCE-207/206 BCE \\
\hline \multirow[t]{3}{*}{ Han dynasty } & Western/Former Han & & 206/202 BCE-CE 9 \\
\hline & Xin dynasty & & CE 9-CE 23 \\
\hline & Eastern/Later Han & & CE 25-CE 220 \\
\hline \multicolumn{3}{|c|}{ Three Kingdoms } & CE 220-CE 280 \\
\hline \multirow[t]{2}{*}{ Jin dynasty } & Western Jin (CE 265/266-CE 316) & & CE 265/266-CE 420 \\
\hline & Eastern Jin (CE 317-CE 420) & $\begin{array}{l}\text { Sixteen Kingdoms } \\
\text { (CE 304-CE 439) }\end{array}$ & \\
\hline \multicolumn{3}{|c|}{ Northern and Southern dynasties } & CE 420-CE 589 \\
\hline \multicolumn{3}{|c|}{ Sui dynasty } & CE 581-CE 618 \\
\hline \multicolumn{3}{|c|}{ Tang dynasties } & CE 618-CE 907 \\
\hline \multicolumn{3}{|c|}{ Five Dynasties and Ten Kingdoms Liao dynasty (CE 907/916-CE 1125) } & CE 907-CE 960/979 \\
\hline \multirow[t]{2}{*}{ Song dynasty } & Northern Song (CE 960-CE 1127) & Western Xia (CE 1038-CE 1227) & CE 960-CE 1279 \\
\hline & Southern Song (CE 1127-CE 1279) & Jin dynasty (CE 1115-CE1234) & \\
\hline \multicolumn{3}{|l|}{ Yuan dynasty } & CE 1271-CE 1368 \\
\hline \multicolumn{3}{|l|}{ Ming dynasty } & CE 1368-CE 1644 \\
\hline \multicolumn{3}{|l|}{ Qing dynasty } & CE 1644-CE 1911/1912 \\
\hline
\end{tabular}

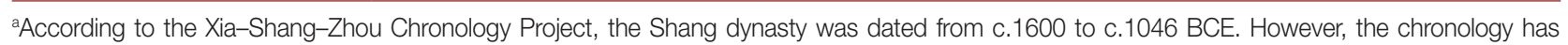
been disputed by many scholars.

cluding the oldest known musical instruments [6]. With regard to parasite evidence, Zhang and colleagues [6] reported that abdominal soil samples were collected from 4 burials at the Jiahu site. On microscopy, they reported finding structures which they believed represent the eggs of roundworm (Ascaris lumbricoides), whipworm (Trichuris trichiura), and tapeworm (Taenia sp.) [7]. However, in our opinion, the illustrations of the proposed eggs published in the paper do not provide strong evidence to confirm such identification. For example, the structure proposed to be a human roundworm egg had the 


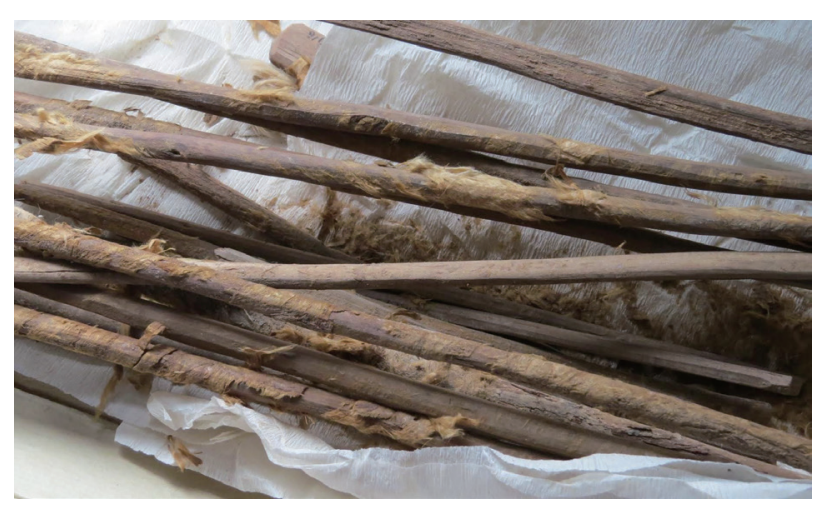

Fig. 1. Personal hygiene sticks from a latrine at Xuanquanzhi Relay Station at Dunhuang on the Silk Road, dating from 111 BCECE 109.

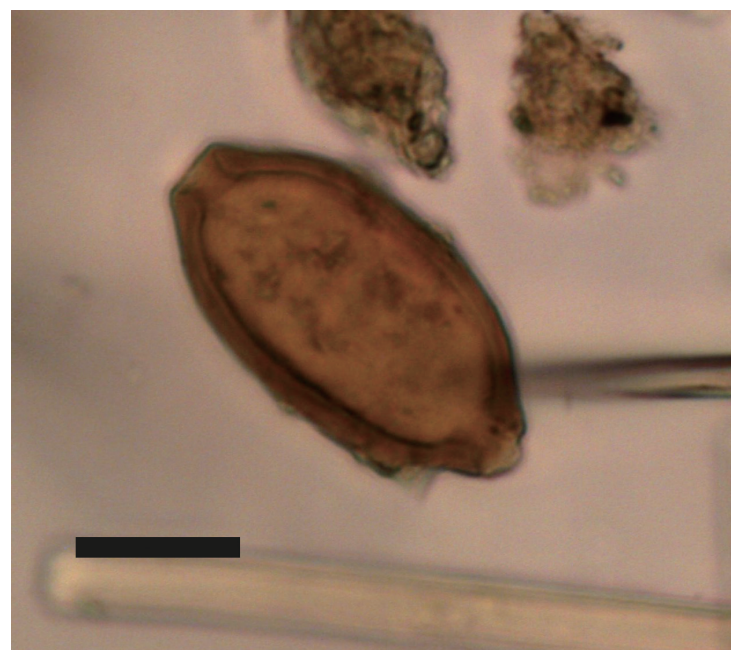

Fig. 2. Whipworm egg (Trichuris trichiura) from the Xuanquanzhi latrine. Dimensions $53 \times 27 \mu \mathrm{m}$. Black scale bar indicates $20 \mu \mathrm{m}$.

dimensions of 122 by $83 \mu \mathrm{m}$, which is too large to be a human roundworm egg. Standard dimensions quoted in the literature for human roundworm eggs are in the range of 45-75 $\mu \mathrm{m}$ in length by $35-50 \mu \mathrm{m}$ in breadth for fertilized eggs, and 85-95 $\mu \mathrm{m}$ by $43-47 \mu \mathrm{m}$ for unfertilized eggs [8]. The proposed whipworm and tapeworm eggs have an appearance more compatible with plant material than parasite eggs.

\section{Ancient China (Early States-Warring States period) (1,900/1,800 BCE-221 BCE)}

The formation of early states, known as Erlitou and Erligang, took place around 1,900/1,800 BCE to 1,250 BCE in the Central Plain in mainland China [5]. During the period from 1,900 BCE to $221 \mathrm{BCE}$, examples of ancient parasites have been reported [9]. Wei et al. [9] examined pelvic soil from 20

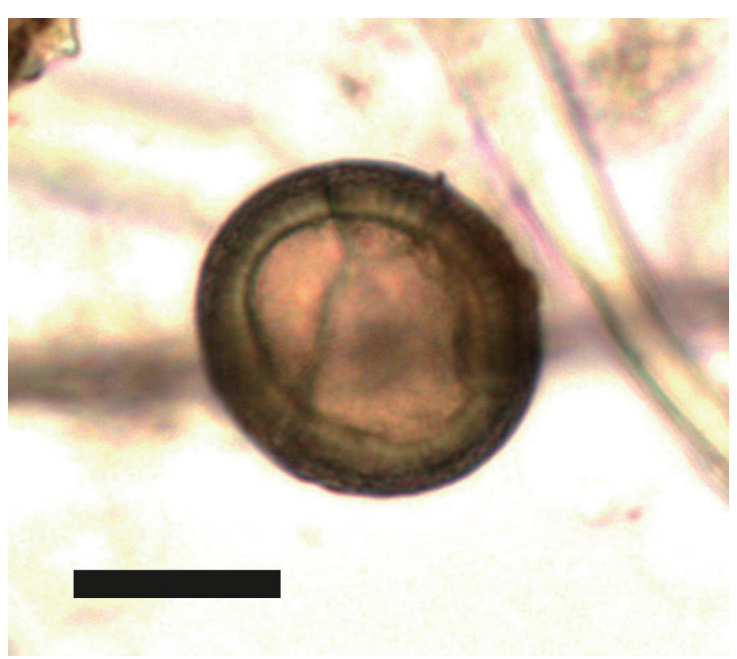

Fig. 3. Taenia sp. tapeworm egg from the Xuanquanzhi latrine. It is most likely to be Taenia asiatica or Taenia solium, and less likely to be Taenia saginata. Dimensions $36 \times 32 \mu \mathrm{m}$. Black scale bar indicates $20 \mu \mathrm{m}$.

inhumation burials at Zhengzhou, Henan Province, dated to the Spring and Autumn period (770/771 BCE-476/403 BCE). Five of these burials (25\%) were positive for roundworm eggs (A. lumbricoides). A total of 34 eggs were identified (18 fertilized and 16 unfertilized roundworm eggs), but they did not specify the number from each of the 5 individuals.

Later, during the Warring States period (5th century BCE$221 \mathrm{BCE}$ ), a female mummy from Jiangling, Hubei Province was found to contain the eggs of Chinese liver fluke (Clonorchis sinensis), whipworm, and roundworm $[10,11]$. Similarly, a female mummy from Jingmen, Hubei Province was found to have Chinese liver fluke as well as whipworm [12].

\section{Imperial China (Qin dynasty-Qing dynasty) (221 BCE-CE 1911/1912)}

A greater number of cases of ancient parasites have been recovered in the period dating from Imperial China. A latrine has been identified in the Xuanquanzhi relay station at Dunhuang in Gansu Province, northwest China. The relay station was built in 111 BCE and used until CE 109 (during the Han dynasty). Xuanquanzhi was positioned on the Silk Road, providing accommodation to travellers and a change of horses for government officials and the postal service. When the latrine was excavated, it was found to contain a significant number of personal hygiene sticks used for wiping after defecation. These wooden sticks had cloth wrapped around one end, and some well-preserved sticks had dried feces still in situ (Fig. 1). When 
Table 3. Species of parasites found in samples from China

\begin{tabular}{|c|c|c|c|}
\hline Parasite Species & Location & Type of samples & No. of individuals affected \\
\hline Ascaris lumbricoides & $\begin{array}{l}\text { Zhengzhou, Henan Province } \\
\text { Xuanquanzhi, Gansu Province } \\
\text { Jiangling, Hubei Province } \\
\text { Jintan, Jiangsu Province } \\
\text { Guangzhou, Guangdong Province } \\
\text { Yangzhou, Jiangsu Province } \\
\text { Fuqing, Fujian Province } \\
\text { Shaowu, Fujian Province } \\
\text { Longyan, Fujian Province }\end{array}$ & $\begin{array}{l}\text { Pelvic soil } \\
\text { Latrine } \\
\text { Mummy }\end{array}$ & 8 \\
\hline Clonorchis sinensis & $\begin{array}{l}\text { Xuanquanzhi, Gansu Province } \\
\text { Guangzhou, Guangdong Province } \\
\text { Hengyang, Hunan Province } \\
\text { Jiangling, Hubei Province } \\
\text { Phoenix Hill, Huibei Province } \\
\text { Fuqing, Fujian Province } \\
\text { Fuzhou, Fujian Province }\end{array}$ & $\begin{array}{l}\text { Latrine } \\
\text { Mummy }\end{array}$ & 6 \\
\hline Enterobius vermicularis & Changsha, Huibei Province & Mummy & 1 \\
\hline Fasciolopsis buski & $\begin{array}{l}\text { Guangzhou, Guangdong Province } \\
\text { Fuqing, Fujian Province }\end{array}$ & Mummy & 2 \\
\hline Schistosoma japonicum & $\begin{array}{l}\text { Phoenix Hill, Huibei Province } \\
\text { Changsha, Huibei Province }\end{array}$ & Mummy & 2 \\
\hline Taenia sp. & $\begin{array}{l}\text { Phoenix Hill, Huibei Province } \\
\text { Xuanquanzhi, Gansu Province }\end{array}$ & $\begin{array}{l}\text { Mummy } \\
\text { Latrine }\end{array}$ & 1 \\
\hline Trichuris trichiura & $\begin{array}{l}\text { Changsha, Huibei Province } \\
\text { Phoenix Hill, Huibei Province } \\
\text { Jintan, Jiangsu Province } \\
\text { Guangzhou, Guangdong Province } \\
\text { Jiangling, Hubei Province } \\
\text { Yangzhou, Jiangsu Province } \\
\text { Fuqing, Fujian Province } \\
\text { Longyan, Fujian Province } \\
\text { Fuzhou, Fujian Province } \\
\text { Xuanquanzhi, Gansu Province }\end{array}$ & Latrine & 10 \\
\hline
\end{tabular}

analyzed, the eggs of whipworm (Fig. 2), roundworm, Taenia sp. tapeworm (Fig. 3), and Chinese liver fluke were identified [13].

A study carried out on a female mummy from the Mawangtui tomb in Changsha, Han Dynasty (206/202 BCE-CE 220), found oriental schistosomiasis (Schistosoma japonicum), whipworm, and pinworm (Enterobius vermicularis) eggs in the fecal material extracted from the intestines [14]. A similar study of a Han dynasty mummy from Phoenix Hill in Huibei Province showed the presence of oriental schistosomiasis, Chinese liver fluke, whipworm, and Taenia sp. tapeworm [15].

In addition to this, the human mummies of several individuals who died in the Ming and Song dynasties have displayed evidence of infection with roundworm, Chinese liver fluke, whipworm, and the giant intestinal fluke Fasciolopsis buski [16]
(Table 3). A map showing the location of all the examples discussed in this paper is given as Fig. 4 .

\section{DISCUSSION}

Having brought together all the available evidence, we can start to investigate which parasites may have been more common than others, if geographical location affected likelihood of infection, and if there seem to be changes in infection over time. However, we do need to be cautious and realistic in how we use this data. A total of 33 individuals and 1 latrine from the whole of ancient China have been analyzed for the eggs of intestinal parasites. These 33 individuals are represented by 13 mummies and 20 skeletonized burials. The time period over which these individuals lived and died is very large, over 3,000 


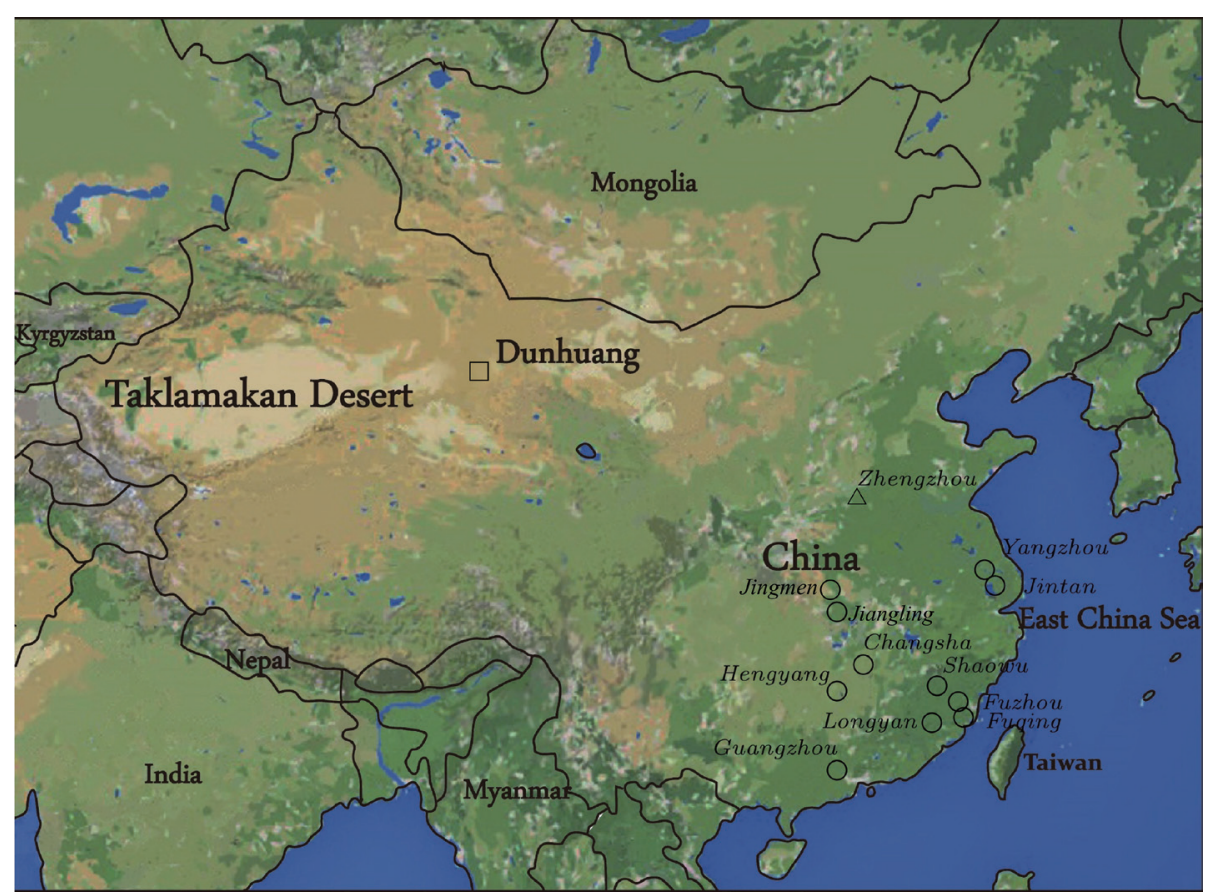

Fig. 4. Map of China showing the location of each site where parasites were found in archaeological material. Round circle indicates a mummy, triangle indicates pelvic soil from burials, and square indicates a latrine.

years. Therefore, we cannot determine past prevalence of diseases in the way we might with much larger samples. Furthermore, many of the samples came from mummies in sophisticated tombs that would suggest they were the burials of wealthy people. This means the findings from the mummy evidence may not necessary apply to those of poor members of the population.

The most common parasites found were those of whipworm, roundworm, and Chinese liver fluke. Whipworm was found in $77 \%$ of the mummies $(\mathrm{n}=10 / 13)$ as well as on the personal hygiene sticks excavated from the latrine at Xuanquanzhi in Gansu Province (111 BCE-CE 109). Roundworm was found in the pelvic soil of $25 \%$ of burials $(n=5 / 20)$ dating from the Spring and Autumn period from Zhengzhou in Henan Province. It was also identified on the Xuanquanzhi latrine sticks, and in $62 \%(\mathrm{n}=8 / 13)$ mummies from across all times periods. Chinese liver fluke eggs were recovered from $46 \%$ of the mummies $(n=6 / 13)$ and the Xuanquanzhi latrine. As whipworm and roundworm are spread by fecal contamination of food, possible explanations for their widespread presence are that in ancient China hands were not washed regularly, that drinking water was contaminated by human feces, or that human feces were being used a crop fertilizer $[17,18]$.

Other species of intestinal parasites seem to have been much less common. Both the flukes F. buski and S. japonicum were found in just $15 \%$ of mummies $(n=2 / 13)$, while pinworm (E. vermicularis) and Taenia sp. tapeworm were found in just $8 \%$ of mummies $(n=1 / 13)$. Taenia sp. was also found on the personal hygiene sticks from the latrine at Xuanquanzhi. If the limited sample we have in this study is in any way representative of the wider population, this would suggest that far fewer people in ancient China might have suffered with these helminths than was the case for whipworm, roundworm, and Chinese liver fluke.

Geographical variation is more of a challenge to assess, as the locations where parasites have been studied are not evenly spread across ancient China. As we can see from our map (Fig. 4), the vast majority of samples came from eastern and southern China. Only 1 sample, the Xuanquanzhi latrine, was in northwest China. This leaves the northeast, north, center, west, and southwest of this huge region devoid of evidence.

It is interesting that $46 \%$ of the 13 mummies were infected with Chinese liver fluke. All the mummies were recovered from regions of China that are lush and well-watered by the Yellow, Yangtze, and Pearl River networks. Chinese liver fluke is found today just in eastern and southern China and Korea, where the life cycle of the parasite can be completed in the local water snails and freshwater fish. It is contracted if a person 
eats raw infected freshwater fish $[19,20]$. The mummies were almost all from the areas of eastern and southern China where we would expect to find the Chinese liver fluke.

In the 20th century, it was found that the region of China with the highest prevalence of Chinese liver fluke was Guangdong Province, with a prevalence of just 1.82\% between 19881992 , and $0.365 \%$ for the whole country [21]. Since $46 \%$ of the ancient mummies were infected, this would suggest either that these mummies were not representative of the population in which they lived, or that there has been a dramatic fall in the prevalence of Chinese liver fluke over this time. If there has been a genuine drop in liver fluke infection, we should ask ourselves if this might be due to advances in medical treatments, hygiene, toilets, and health education over this time. However, in the same 20th century survey, the prevalence of roundworm was $47 \%$ in China [21]. This is not that dissimilar to the $62 \%$ of ancient mummies infected by roundworm. This data suggests that while roundworm remained common in China for many centuries up to and including the late 20th century, Chinese liver fluke may have been much more common over the last 2,000 years than it was in the late 20th century. It seems unlikely that this change in Chinese liver fluke infection was due to advances in medicine and sanitation, as we would expect roundworm to have become rarer as well if that was the case. More likely explanations for this apparent change in prevalence for the liver fluke, but not roundworm, could be that this indicates either a change in the way freshwater fish was processed or eaten by Chinese people in the late 20th century compared with the previous 2,000 years, or that modern pollution in Chinese rivers has affected the intermediate hosts, such as water snails that are required for the transmission of this flatworm to humans.

The DNA of the Chinese liver fluke from the Phoenix Hill mummy (167 BCE) has been the focus of research. Samples from the gall bladder underwent genomic analysis, and the internal transcribed spacers 1 and 2 (ITS1 and ITS2) in ribosomal genes were sequenced. It was found that while ITS2 sequences were identical to modern strains of Chinese liver fluke, the ITS2 sequence differed by 15 nucleotides. It was proposed that this indicates the parasite has evolved over the last 2,000 years [22].

Taenia sp. tapeworm eggs of different species appear very similar on microscopy, so without DNA analysis, it is not possible to distinguish Taenia saginata contracted from eating beef, from Taenia solium and Taenia asiatica contracted from eating pork. However, written records from ancient China show that pork was widely eaten, and that beef was rare in the diet as cattle were used for their strength pulling farm machinery $[23,24]$. This might suggest that the infections noted were likely to have been due to either T. asiatica or T. solium, and not $T$. saginata. Texts written on Han Dynasty bamboo slips have described how it was common for pigs to be reared in captive environments where they would not be able to violate laws by disrupting crops [25]. Pig-shaped burial goods from a tomb dating from the Han Dynasty serves as an indication of the extent to which the pig was an important resource as a food product and as part of daily life in the period [26].

Chinese communities started to consume animal viscera in the period from the 11th century BCE to $221 \mathrm{BCE}$, in the Zhou Dynasty. The Book of Rites, a compilation of written accounts relating to aspects of conduct in society and to the ceremonial rights of the Zhou Dynasty, recorded that the roasted liver of a dog was considered to be a delicacy [27]. A noteworthy discovery was made the excavation of Mawangdui in central China. This excavation explored the burial places of elites dating from the Han Dynasty, and it gained widespread fame as a result of the recovery of an excellently preserved mummified female body. Numerous burial items of considerable value included models of animal viscera, including liver, stomach, lungs, and spleen $[28,29]$. The Book of Han (dating from CE 32-92) also referred to the consumption of sliced liver, bacon, incompletely cooked and roasted animal products, and dog and pig viscera $[23,30]$. These references are an indication of the widespread nature of these dietary habits over this period. In light of this, the identification of Taenia sp. tapeworm eggs in the Xuanquanzhi latrine and a Han dynasty mummy potentially reflect the well documented dietary practices of consuming raw pig viscera.

The Silk Road was a well-known long distance transport route that came to prominence during the Han dynasty (206/202 BCE-CE 220). It connected eastern China with central Asia, the Middle East, and Europe, and in its entirety was about $7,000 \mathrm{~km}$ in length $[2,31]$. It has been proposed to have acted as a route via which diseases, such as bubonic plague, anthrax, and leprosy might have spread between Asia and Europe [3234]. However, the evidence supporting this hypothesis is based upon genetic similarity between bacterial strains in East Asia and Europe [35,36]. It remained unknown whether transmission was along the Silk Road itself, or to the north via Mongolia and Russia, or to the south via India. Past research using 
parasites as markers of migration to and from Asia include movement between Europe and the Middle East in the 15th century $\mathrm{AD}$, and between China and America in the 19th century $[37,38]$. A study of the latrine at Xuanquanzhi relay station has for the first time allowed an investigation of an archaeological site on the Silk Road that was built for travellers. The presence of Chinese liver fluke on the personal hygiene sticks in the latrine is an important finding. This relay station at Dunhuang is located in an arid region of northwest China, at the eastern end of the Tamrin Basin. This basin contains the Taklamakan Desert, and is far too dry a region for the Chinese liver fluke to be able to complete its life cycle. Indeed, Dunhuang is 1,500 km away from any region where the Chinese liver fluke was endemic in the 20th century [21]. This suggests that a traveller from the well-watered areas of eastern or southern China contracted the parasite there, and travelled a huge distance along the Silk Road before using the latrine at Xuanquanzhi relay station. This provides the first archaeological evidence from along the Silk Road to show that ancient travellers were moving with their infectious diseases [13].

\section{CONCLUSION}

Here we have brought together the available evidence for intestinal parasites in ancient China and used this to better understand the consequences of infection for the people living in the region. We have been cautious in our interpretation due to the limited sample size and the long period over which the archaeological evidence originates. However, we have been able to draw some fascinating conclusions. Seven species of intestinal parasites have been identified in ancient China, but it was found that whipworm, roundworm, and Chinese liver fluke seem to have been by far the most common. Indeed, around a half to $3 / 4$ of Chinese mummies so far studied have been infected by these parasites. While whipworm and roundworm remained common in Chinese people in the late 20th century, Chinese liver fluke had become much less common by then. This might suggest a reduction in the amount of raw freshwater fish eaten over time, or pollution in modern Chinese rivers. We have also seen evidence for the migration of people along the Silk Road with their parasites 2,000 years ago, with the discovery of Chinese liver fluke in a latrine in northwest China $1,500 \mathrm{~km}$ outside its endemic area. It is hoped that in the future Chinese archaeologists will start to sample the contents of latrines at the time of their excavation, so that we can increase our evidence base and enable us to create a much more reliable interpretation of intestinal parasite infection in past Chinese populations.

\section{CONFLICT OF INTEREST}

We have no conflict of interest related to this study.

\section{REFERENCES}

1. Harris DR. The Origins and Spread of Agriculture and Pastoralism in Eurasia: Crops, Fields, Flocks and Herds. London, UK. UCL Press. 1996.

2. Boulnois L, Mayhew B. Silk Road: Monks, Warriors and Merchants on the Silk Road. Sheung Wan, Hong Kong. Odyssey. 2005.

3. Seo M, Shin DH. Parasitism, cesspits and sanitation in East Asian countries prior to modernisation, In Mitchell PD ed, Sanitation, latrines and intestinal parasites in past populations. Farnham, UK. Ashgate. 2015, pp 150-164.

4. Mitchell PD. The origins of human parasites: exploring the evidence for endoparasitism throughout human evolution. Int J Paleopathol 2013; 3: 191-198.

5. Liu L, Chen X. The Archaeology of China: From the Late Paleolithic to the Early Bronze Age. Cambridge, UK. Cambridge University Press. 2012.

6. Zhang J, Harbottle G, Wang C, Kong Z. Oldest playable musical instruments found at Jiahu early Neolithic site in China. Nature 1999; 401: 366-368.

7. Zhang J, Ren Q, Weng Y, Lan W, Xue Y, Jia N. Ancient parasite research of pelvic soil of burials from the Jiahu site. Cultural Relics of Central China 2006; 3: 86-90 (in Chinese).

8. Garcia LS. Practical Guide to Diagnostic Parasitology. Washington DC, USA. ASM Press. 2009.

9. Wei YY, Weng Y, Zhang JZ, Fan WQ, Xin YJ. Archaeoparasitological report on abdominal burial soil from the Zhengzhou Jinshui and Xinzheng Lihe cemeteries. Acta Anthropol Sin 2012; 31: 415-423 (in Chinese).

10. Lei S, Hu SY. The discovery of parasite eggs in an ancient corpse from Zhangguo Chu Tomb No. 1 in the Mashan brick-field of Jiangling County, Hubei. Chin J Parasitol Parasit Dis 1984; 1: 8 (in Chinese).

11. Yang WY, Wei DX, Song GF, Wu ZB, Teng RS. Study on the parasitology in an ancient corpse from Zhangguo Chu Tomb No. 1 in the Mashan brick-field of Jiangling County, Hubei. Journal of Huazhong University of Science and Technology: Med Sci 1984; 1: 43-46 (in Chinese).

12. Wu ZB, Guan Y, Zhou ZB. Study of an ancient corpse of the Warring States period unearthed from Tomb No. 1 at Guojiagang in Jingmen, Hubei: a comprehensive study. J Chin Electron Microscopy Soc 1995; 4: 312-316 (in Chinese). 
13. Yeh HY, Mao R, Wang H, Qi W, Mitchell PD. Early evidence for travel with infectious diseases along the Silk Road: Intestinal parasites from 2000 year-old personal hygiene sticks in a latrine at Xuanquanzhi Relay Station in China. J Archaeol Sci 2016 (in press).

14. Wei O. Internal organs of a 2100-year-old female corpse. Lancet 1973; 2: 1198.

15. Wei DX, Yang WY, Huang SQ, Lu YF, Su TC, Ma JH, Hu WX, Xie NF. Parasitological investigation on the ancient corpse of the Western Han Dynasty unearthed from tomb no. 168 on Phoenix Hill in Jiangling county. Acta Acad Med Wuhan 1981; 1: 1623.

16. Li Y. Summary of parasitic research on corpses in China. Acta Anthropol Sin 1984; 3: 407-411 (in Chinese).

17. Ziegelbauer K, Speich B, Mäusezahl D, Bos R, Keiser J, Utzinger J. Effect of sanitation on soil-transmitted helminth infection: systematic review and meta-analysis. PLoS Med 2012; 9: e1001162.

18. Heinonen-Tanski H, van Wijk-Sijbesma C. Human excreta for plant production. Bioresour Technol 2005; 96: 403-411.

19. Schmidt GD, Roberts LS. Foundations of Parasitology. New York, USA. McGraw-Hill. 2006.

20. Qian MB, Utzinger J, Keiser J, Zhou XN. Clonorchiasis. Lancet 2016; 387: 800-810.

21. Yu SH, Xu LQ, Jiang ZX, Xu SH, Han JJ, Zhu YG, Chang J, Lin JX, $\mathrm{Xu}$ FN. First report of a national survey of the distribution of human parasites I: geographical distribution of parasites. Chin J Parasitol Parasit Dis 1994; 12: 241- 247 (in Chinese).

22. Liu WQ, Liu J, Zhang JH, Long XC, Lei JH, Li YL. Comparison of ancient and modern Clonorchis sinensis based on ITS1 and ITS2 sequences. Acta Trop 2007; 101: 91-94.

23. Li H. History of the Food Culture of the Han and Tang Dynasties. Beijing, China. Beijing Normal University Publishing Group. 1997 (in Chinese).

24. Yu B. The golden age of Chinese feasting: antiquities from a Mawangdui tomb and the culinary culture of the Han Dynasty. Collectors 2010; 17: 35-42 (in Chinese).

25. Hou Z. On the pig culture of the Han Dynasty written on bamboo and silk slips. Ancient and Modern Agriculture 2012; 92: 47-52 (in Chinese).

26. Li R. Funeral Customs of the Han Dynasty. Shenyang. Shenyang Press. 2003 (in Chinese).

27. Liu P. History of Chinese chop suey. Quarterly of the Foundation of Chinese Dietary Culture 2004; 10: 23-28 (in Chinese).

28. HPM, IACASS. Tomb \#1 of Mawangdui at Changsha, Han Dynasty. Beijing. Cultural Relics Press. 1973 (in Chinese).

29. HPM, IACASS. Brief report on the excavation Tombs \#2 and \# 3 of Mawangdui, Han Dynasty. Cultural Relics 1974; 7: 39-48, 63, 95-111 (in Chinese).

30. Jiang H. Discussion of dietary culture of the Han Dynasty from archaeological data. Chin Cuisine Res 1995; 12: 17-22 (in Chinese).

31. Bonavia J, Lindesay W, Qi W. The Silk Road from Xi'an to Kashgar. Hong Kong. Odyssey. 2004.

32. Schmid BV, Büntgen U, Easterday WR, Ginzler C, Walløe L, Bramanti B, Stenseth NC. Climate-driven introduction of the Black Death and successive plague reintroductions into Europe. Proc Natl Acad Sci USA 2015; 112: 3020-3025.

33. Monot M, Honore N, Garnier T, Zidane N, Sherafi D, PanizMondolfi A, Matsuoka M, Taylor GM, Donoghue HD, Bouwman A, Mays S, Watson C, Lockwood D, Khamispour A, Dowlati Y, Jianping S, Rea TH, Vera-Cabrera L, Stefani MM, Banu S, Macdonald M, Sapkota BR, Spencer JS, Thomas J, Harshman K, Singh P, Busso P, Gattiker A, Rougemont J, Brennan PJ, Cole ST. Comparative genomic and phylogeographic analysis of Mycobacterium leprae. Nat Genet 2009; 41: 1282-1289.

34. Simonson TS, Okinaka RT, Wang B, Easterday WR, Huynh L, U'Ren JM, Dukerich M, Zanecki SR, Kenefic LJ, Beaudry J, Schupp JM, Pearson T, Wagner DM, Hoffmaster A, Ravel J, Keim P. Bacillus anthracis in China and its relationship to worldwide lineages. BMC Microbiol 2009; 9: 71.

35. Morelli G, Song Y, Mazzoni CJ, Eppinger M, Roumagnac P, Wagner DM, Feldkamp M, Kusecek B, Vogler AJ, Li Y, Cui Y, Thomson NR, Jombart T, Leblois R, Lichtner P, Rahalison L, Petersen JM, Balloux F, Keim P, Wirth T, Ravel J, Yang R, Carniel E, Achtman M. Yersinia pestis genome sequencing identifies patterns of global phylogenetic diversity. Nat Genet 2010; 42: 1140-1143.

36. Wagner DM, Klunk J, Harbeck M, Devault A, Waglechner N, Sahl JW, Enk J, Birdsell DN, Kuch M, Lumibao C, Poinar D, Pearson T, Fourment M, Golding B, Riehm JM, Earn DJ, DeWitte S, Rouillard JM, Grupe G, Wiechmann I, Bliska JB, Keim PS, Scholz HC, Holmes EC, Poinar H. Yersinia pestis and the plague of Justinian 541-543 AD: a genomic analysis. Lancet Infect Dis 2014; 14: 319-326.

37. Yeh HY, Prag K, Clamer C, Humbert JB, Mitchell PD. Human intestinal parasites from a Mamluk Period cesspool in the Christian quarter of Jerusalem: potential indicators of long distance travel in the 15th century AD. Int J Paleopathol 2015; 9: 69-75.

38. Reinhard KJ, Araújo A, Sianto L, Costello JG, Swope K. Chinese liver flukes in latrine sediments from Wong Nom's property, San Bernandino, California: Archaeoparasitology of the Caltrans District headquarters. J Parasitol 2008; 94: 300-303. 